\title{
علم المعاني وتعليمه لغير الناطقين باللغة العربية
}

\author{
Ahmad Taufiq, Muhammad Ulil Fahmi \\ Institut Agama Islam Negeri Pekalongan \\ Ahmad.taufiq@iainpekalongan.ac.id, fahmimuhammed@gmail.com
}

\begin{abstract}
Abstrak
lmu Ma'ani sebagai salah satu bagian yang esensial dari Ilm alBalaghah, ilm al- ma'any merupakan ilmu dimana dengan ilmu tersebut pembelajar dapat mengetahui keadaan-keadaan perkataan dalam bahasa Arab yang sesuai dengan muqtadha al-hal (situasi dan kondisi). Tujuan dari penelitian ini adalah mengungkap tentang ilmu ma' ani dan pembelajaranya bagi penutur non Arab, sementara itu Ilm al-Ma'ani ditafsirkan sebagai sebuah pengetahuan yang meneliti tentang struktur kalimat yang tujuanya untuk menghindari perbedaan antara pembicara dan pemahaman pendengar. Mengajar Ilm al-Ma'ani, lebih khusus lagi, memiliki dua tujuan; pertama, mengekspresikan maksud teks Arab. Kedua, menganalisis teks Arab. Dalam penelitian ini akan dibahas terkait dengan pengertian ilmu ma'any,tema-tema (maudhu'at) yang ada dalam pembelajaran ilmu ma'any dan cara mengajarkan ilm alma'any bagi penutur non Arab. Alternatif pembelajaran Ilm alma'any menjadi solusi yang terbaik yang sangat diharapkan dalam proses pembelajaran dalam mata kuliah ilm al-ma'any. Penelitian yang dilakukan penulis adalah jenis penelitian kualitatif. Ditinjau dari sifatnya, penelitian ini bersifat kajian kepustakaan (library research). Sementara metode penelitian yang peneliti gunakan dalam penelitian ini adalah metode Analisis Isi (Content Analysis).
\end{abstract}

Kata kunci : ilm al-ma'any, Pembelajaran Balaghah 


\section{ملخص}

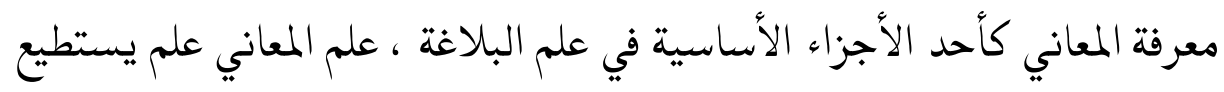

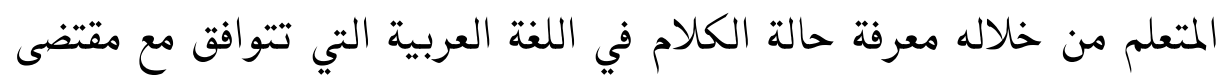
الأمور . . الغرض من هذا البحث هو الكثف عن معرفة المعاني ومتعلميها لغير

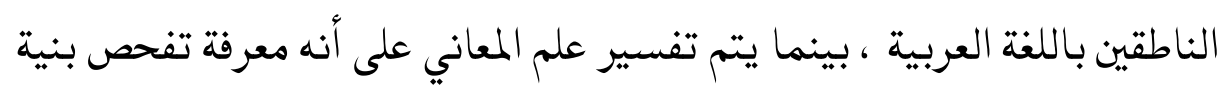
الجملة من أجل تجنب الاختلافات بين فهم المتحدث والمستمع • تعليم علم المعاني

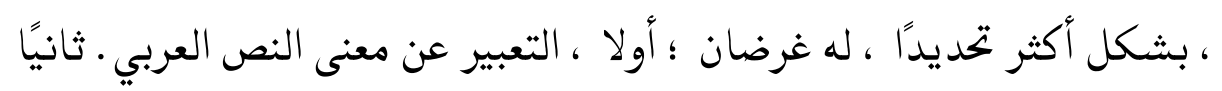
، تحليل النص العربي • سنناقث في هذا البحث فهم معرفة المعاني ، والموضوعات (المذكرات) في تعلم معرفة المعاني وكيفية تدريس علم المعاني لغير الناطقين باللغة العربية. التعلم البديل علم المعاني هو الحل الأفضل المتوقع في عملية التعلم في دورة علم المعاني . البحث الذي أجراه المؤلف هو نوع من البحث النوعي ـ من طبيعته ، هذا البحث هو بحث مكتبة ـ وفي الوقت نفسه ، كانت طريقة البحث التي استخدمها الباحثون في هذه الدراسة هي طريقة تحليل المحتوى. الكلمات المفتاحية : علم المعاني, تعليم البلاغة

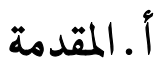

إنّ اللغة كما قال ابن جني هي "أصوات يعبر بها كل قوم عن

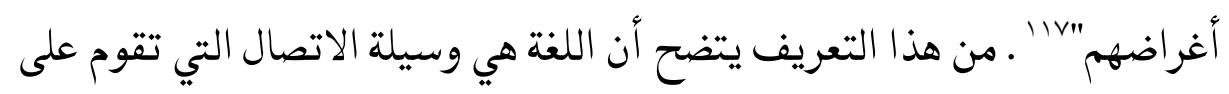
شيئين أساسيين فهما اللفظ والغرض. اللفظ هو الكلام المنطوق والغرض هو

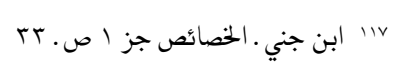


علم المعاني وتعليمه لغير الناطقين باللغة العربية : Ahmad Taufiq, Muhammad Ulil Fahmi

المعنى المقصود ـ ومسألة العلاقة بين اللفظ والمعنى من المسائل اللغوية التي تؤدي إلى ظهور علوم اللغة المتعددة"' . فظهور علم المعاني هو من أجل البحث حول العلاقة بين اللفظ والمعنى في عملية التخاطب ليحترز المتكلم في تأدية المعنى لإيصاله إلى ذهن السامع • فهذا العلم يرشد المتكلم إلى إلى إختيار التركيب اللغوي المناسب للموقف، ويرشده أيضا إلى اختيار الصورة اللفظية أقرب ما تكون دلالة على الفكرة التي تخطر في أذهانهم، حتى يكون ما يُنْثيىُ من كلامٍ أدبي بِِِيفاً . فيعرف بهذا العلم أن خطاب الذكي يباين خطاب الغبي • وعلم المعاني هو واحد من علوم اللغة العربية وهو من المصطلحات التي

أطلقها البلاغيون على مباحث بلاغية تتصل بدراسة أحوال اللفظ العربي التي بها يطابق مقتضى الحال. أي هو العلم الذي يبحث أحوال اللفظ مثل التعريف، والتنكير والذكر والحذف ، والإظهار والإضمار ، وغير ذلك، ويتبين كيف تكون هذه الأحوال واقعة في الكام موقعا تطابق دواعي النفس؟ ولم تأت زائدة ثقيلة ، ولا متكلفة كريهة.

لذا، هناك مشكالات في دراسة اللغة العربية خاصة عند الدارسين غير الناطقين بها لكونها لغة أجنبية . علاوة على ذلك، فإن دراسة هذه اللغة من ناحية

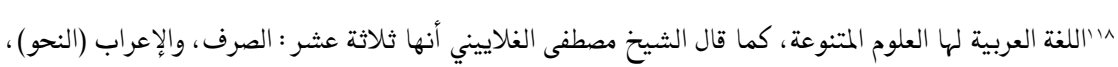

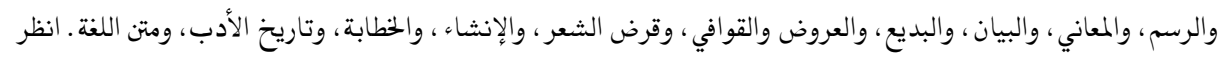

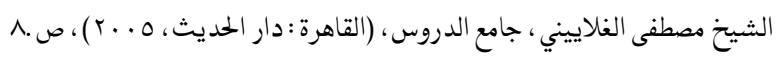


علم المعاني وتعليمه لغير الناطقين باللغة العربية : Ahmad Taufiq, Muhammad Ulil Fahmi

علم المعاني ليست دراسة منطيقية فحسب بل هي دراسة ذوقية تتعلق

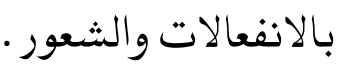

ب. المعلومات النظرية

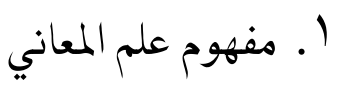

علم المعاني هو فرع من فروع علم البلاغة. وهو العلم الذي يعرف به

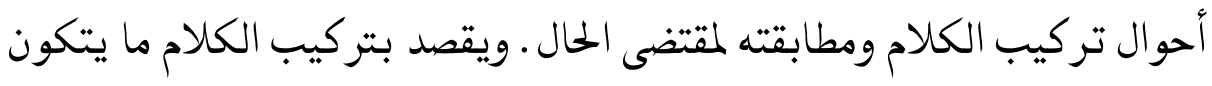
منه بدءا بالكلمة من حيث نوعها وطريقة التعبير بها ومن ثم الجملة اسمية

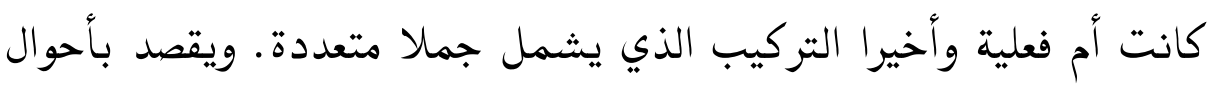
تراكيب الكلام هي ما يتصل بالجملة وأجزائها من تقديم وتأخير، وذكر بمرير وحذف، وتعريف وتنكير .

ويعرّف عبد الرحمن الميداني علم المعاني بأنه "علْمُ يعرف به أحوال

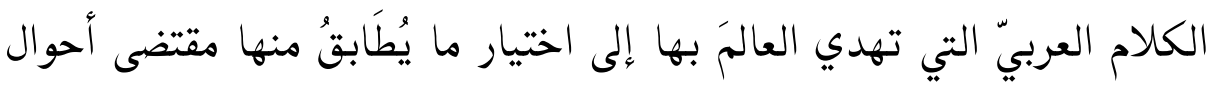

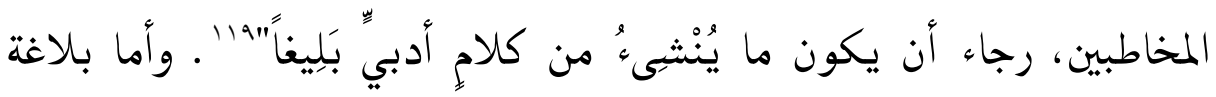
الكلام فهي مطابقته لمتتضى الحال مع فصاحته ومقتضى الحال مختلف فإن مقامات الكلام متفاوتة فمقام التنكير يباين مقام التعريف ومقام الإطلاق يباين مقام

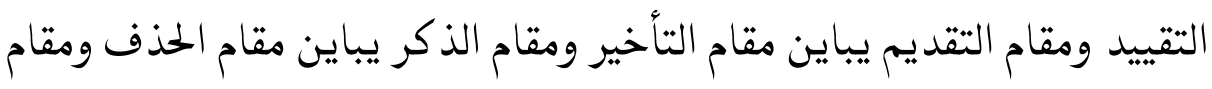
القصر يباين مقام خلافه ومقام الفصل يباين مقام الوصل ومقام الإيجاز يباين

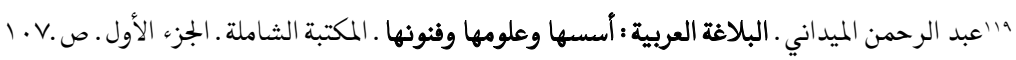

\section{IHTIMAM}


مقام الإطناب والمساواة. وكذا خطاب الذكي يباين خطاب الغبي • وكذا لكل كلمة مع صاحبتها مقام إلى غير ذلك. فمقتضى الحال هو الاعتبار المناسب وهذا 'أعني تطبيق الكلام على مقتضى الحال.r' .

فيتضح من ذلك، أن علم المعاني هو العلم الأساسي في عملية

التخاطب. فيرى أسراري بأن علم المعاني يساوي بـ pragmatik من الناحية النظرية، فالمساواة بينهما تقع في التعريف والخصائص. فالمعاني يختلف بعلم الدلالة semantics . وعلم الدلالة يتعلق بتعيين معني الكلام في سياق الكلام نفسه (السياق الداخلي)، وأن علم المعاني يبحث في مطابقة الكلام بالسياق وبمقتضى الحال (السياق الاجتماعي) • والبراغماتية عند ليفينسون Levinson هو تحليل العلاقة بين اللغة والسياق ليكون أساسا في فهم معنى اللغة pragmatics is the study of relations between language context that ) - 'M (are basic to an account of language understanding وعلم المعاني أقرب علاقة بعلم النحو ، إذا كانت الثركة في دراسة الجملة قائمة بين علم النحو وعلم المعاني فإن النحو يبدأ بالمفردات وينتهي إلى الجملة الواحدة، على حين يبدأ علم المعاني بالجملة الواحدة وقد يتخطاها إلى علاقاتها بالجمل الأخرى في السياق التي هي فيه ـوقال عبد القاهر الجرجاني أن

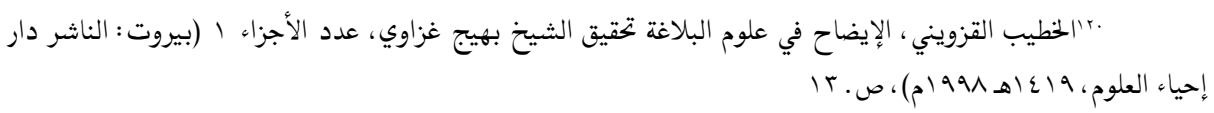

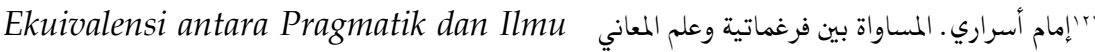
Máani 
علم المعاني وتعليمه لغير الناطقين باللغة العربية : Ahmad Taufiq, Muhammad Ulil Fahmi

العمين متكاملان بحيث لا يستغني أحدهما عن الآخر ، فالنحو بغير المعاني جفاف قاحل، والمعاني بغير النحو أحلام طافية، ينأى بها الوهم عن رصانة المطابقة العرفية، وينحاز بها إلى نزوات الذوق الفردي بr . .

رغم أن المعاني قريب بعلم النحو لكنه يكتلف من ناحية الوظيفة، علم

النحو يبحث في جملة واحدة من المعنى الوضعي وآما علم المعاني فيبحث في جملة أم جمل مطابقا بسياق الكالام. فتوجد المعاني مختلفة بين كل الجملة. على سبيل المثال، فإذا أراد الكاتب أن يصوغ جملة يبيّن فيها طلوع القمر أو عدمه، وجد نفسه أمام عَددٍ من الاحتمالات كما يلي :

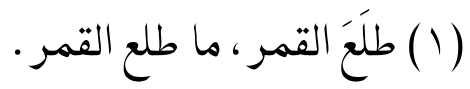

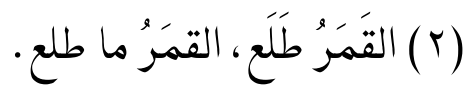
(r) القَمَرُ طَالِعٌْ. القمر غير طالع • ليس القمر طالعا .

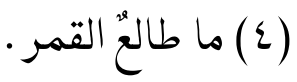

ولكن هل هذه الصيخ تقع في درجة واحدة من البيان ، أم هي مختلفة، مع جوازها جميعا في اللّسان العربي؟ يقول النحويّ هذه كلها جائزة، ولكل منها عندي تخريج إعرابي لكنّ البلاغيَّ يقول : إن صيخ "طَلَعَ القمر - ما طَلَع القمر - ما طالعٌ القمر " تقال في مقام الإخبار الابتدائي الذي لا حاجة فيه إلى تأكيد ، أما صيخ "القَمَرُ طَلَع - القمرُ ما طَلَع - ليس القمرُ طَالعاً" فتقال في مقام 
يحتاج فيه الخبر إلى نوع تأكيد ، فإذا لم تكن حال المخاطب تقتضي تأكيدا فلا داعي لاستخدام هذه الصيغ ، إذ جاء فيها إسناد الطلوع إلى القمر مرّتين، فالقمر

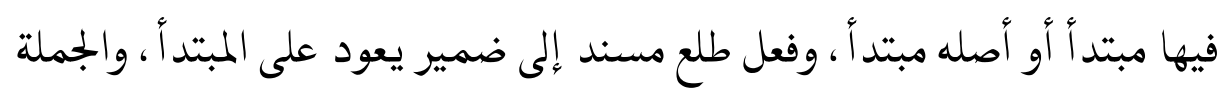

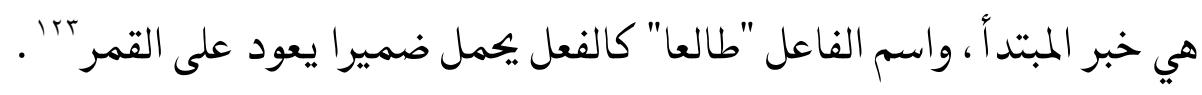
فعلم المعاني يبحث حول العلاقة بين اللفظ والمعنى في عملية

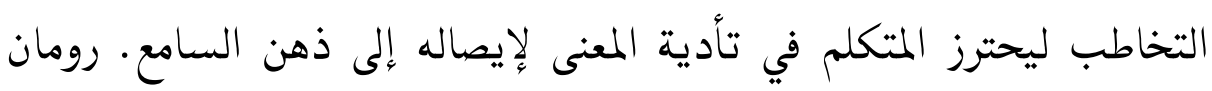

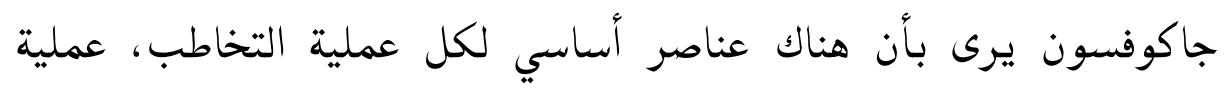
التخاطب عنده هي إرسال الرسالة من المتكلم إلى المخاطب. فعناصر التخاطب

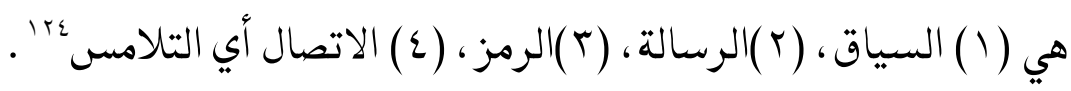

r ب إن موضوعات علم المعاني

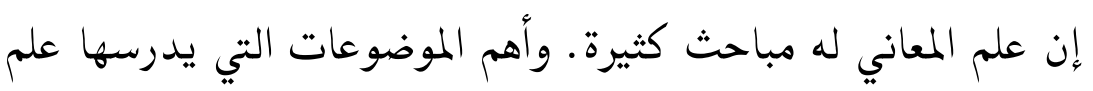
المعاني - كما قد حصرها البلاغيون - هي ثمانية أبواب : (1) أحوال الإسناد

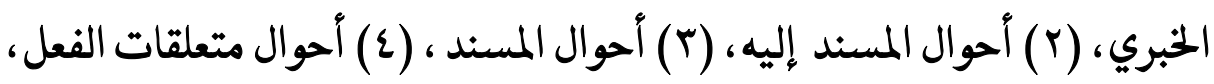
(0) القصر ، (1) الإنثاء ، (V) الفصل والوصل، (1) الإيجاز والإطناب.

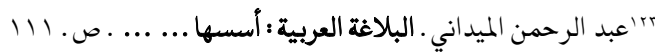

124Panuti Sudjiman dan Aart Van Zoest, et. all. Serba-Serbi Semiotika, (Jakarta: Gramedia Pustaka, 1992), h. 69-70 
علم المعاني وتعليمه لغير الناطقين باللغة العربية : Ahmad Taufiq, Muhammad Ulil Fahmi

وهذه الأبواب الثمانية تولدت من جولان نظر البلاغيين في العبارة،

وارتبط بعضها ببعض وارتباط وثيقا ـ فالجملة تتكون من مسند إليه ، ومسند ،

$$
\text { وإسناد ، فهذه ثلاثة أبواب. }
$$

وإذا كان المسند فعلا ، أو شبهه تعلق به كلام آخر له أحوال، فهذا هو

باب أحوال متعلقات الفعل. وقد يرد الكالام على طريقة القصر ، ثم إن علاقة الجملة بالجملة قد تقتضي وصلها بها أو فصلها عنها ، فهذا باب سادس.

ثم إن مجموع الجمل ينظر إليها من ناحية طولها ، أو قصرها بالنسبة

$$
\text { للمعنى أعني ؛إبجازها ، أو إطنابها فهذا باب سابع. }
$$

وقد يكون الكلام على طريقة الإنثاء أي ليست له نسبة تطابقه آو لا

تطابقه كالأمر ، والنهي فهذا باب ثامن.

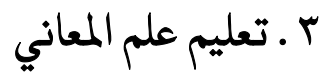

ومن المعلوم بـه أن عملية التعليم لها عناصر أو مكونات منظمة وهي

الأهداف، والمدرس، والدارس، والمادة، والطريقة التعليمية، والوسائل

التعليمية ، والأجهزة التسهيلية، والبيئة ، والتقويم • فتعليم علم المعاني لا بد من

أن تتوفر هذه العناصر في عملية تعليمه . وإليك بيان أهمّ عناصر منها وهي كما 


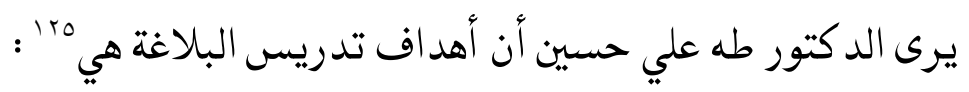

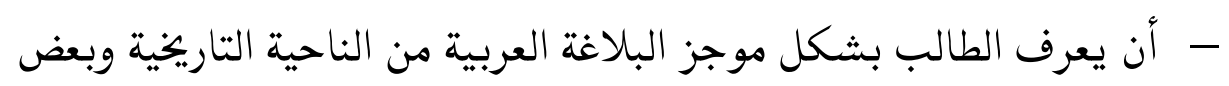

$$
\text { البلاغيين المثهورين ومصنفاتهم البلاغية؛ }
$$

- أن يلم بالبيان العربي وقدرته على كثف مواطنه في النصوص الأدبية؛ - أن يلم بمعاني الجمل الخبرية والإنشائية؛

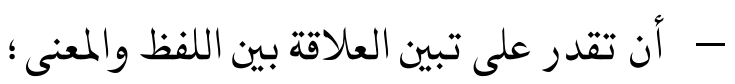

- أن يقدر على تبين العلاقة بين التركيب اللغوي والمعنى

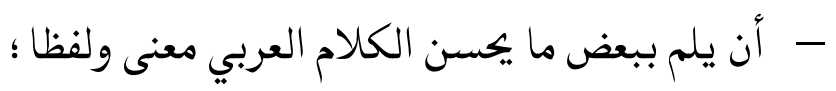

هذه الأهداف هي أهداف عامة لتدريس البلاغة بعلومها الثلاثة. وأما

الأهداف الخاصة لتعليم علم المعاني فهي كما يلي :

- أن يقف الطالب على مظاهر جمال اللغة العربية وروعة بيانها ؛

- أن يتعرف على مفهوم البلاغة، وفوائد دراستها ؛

- أن يتعرف فصاحة الكلمة المفردة ودقة استعمالها ؛

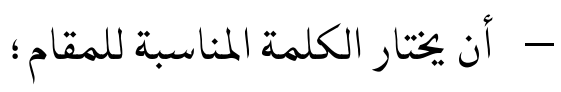

- أن يميز بين مفهومي الخبر و الإنثاء ؛ أن أنساء

- أن يبين أغراض الخبر ومؤكداته؛

1190 طه علي حسين الدليمي . المرجع السابق . 9. 
علم المعاني وتعليمه لغير الناطقين باللغة العربية : Ahmad Taufiq, Muhammad Ulil Fahmi

- أن يميز بين أنواع الإنثاء الطلبي؛

- أن يوضح أهم المعاني التي يخرج إليها الأمر ، والنهي و الاستفهام؛

- أن يستعمل الأمر والنهي و الاستفهام وفق المعاني التي تخرج إليها ؛ - أن يجسن بين تنويع الخبر و الإنشاء؛ - أن يقدم الكلمة أو يؤخرها بحسب المقتضي البلاغي؛ - أن يذكر الكلمة أو يحذفها بحسب المقتضي البلاغي؛ - أن يعين أسلوب القصر مبينًا طرقه و أغراضه البلاغية؛ - أن يستعمل الإيجاز و الإطناب بحسب المقتضي البلاغي؛ - أن يحلل نصوصاً أدبية تحليلاً بلاغياً في ضوء ما درسه في علم المعاني؛ r المواد الدراسية لتعليم علم المعاني

إذا تأمل الكاتب إلى الأهداف الخاصة لتعليم علم المعاني وموضوعات هذا العلم، فيمكن للمدرس أن يصمم المواد الدراسية، كما هو مكتوب في

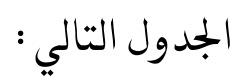


علم المعاني وتعليمه لغير الناطقين باللغة العربية : Ahmad Taufiq, Muhammad Ulil Fahmi

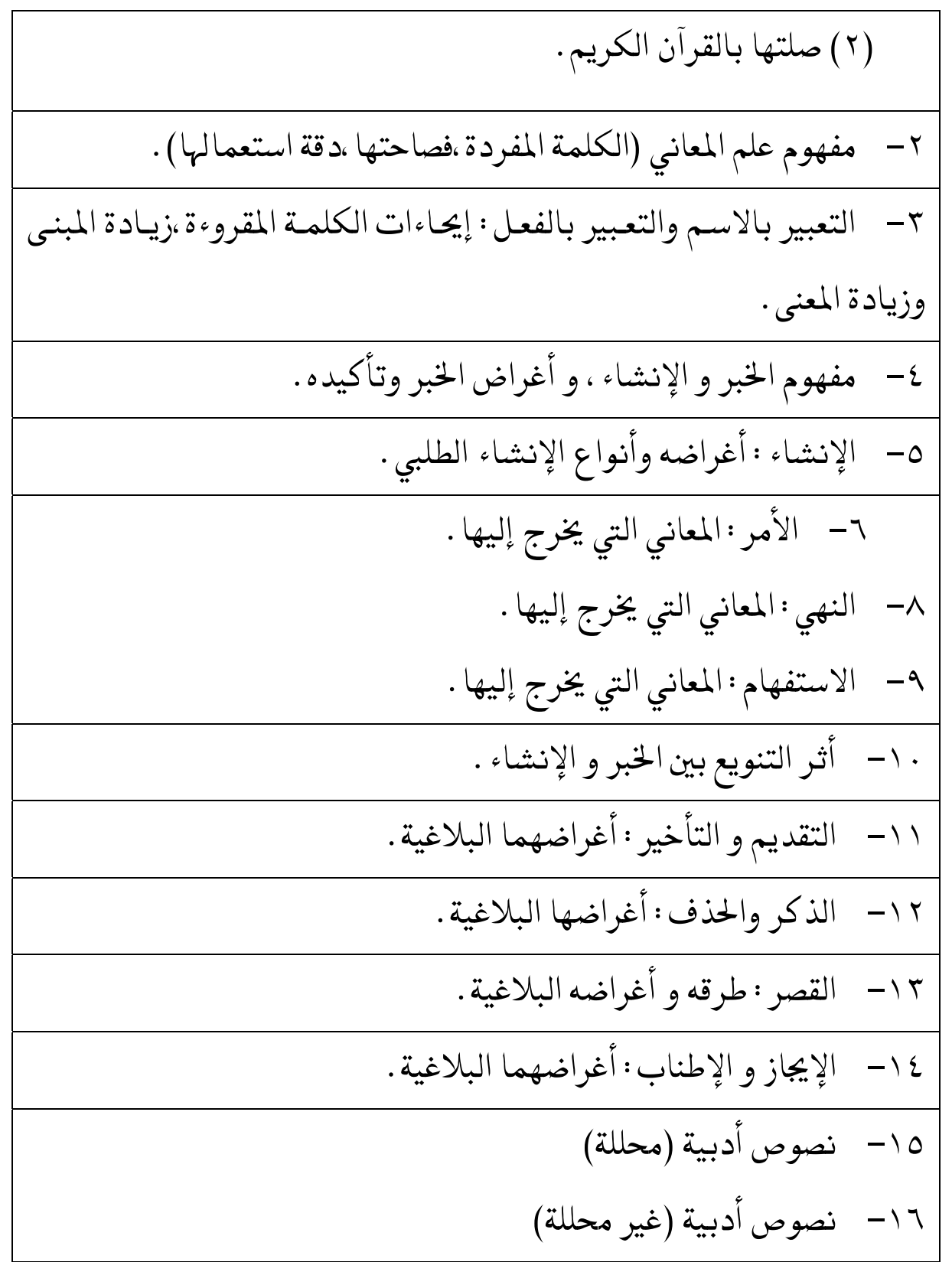


علم المعاني وتعليمه لغير الناطقين باللغة العربية : Ahmad Taufiq, Muhammad Ulil Fahmi

r ) طريقة تعليم علم المعاني

طريقة التعليم بمفومها الواسع تعني مجموعة الأساليب التي يتم

بواسطتها تنظيم المجال الخارجي للمتعلم من أجل تحقيق أهداف تربوية معينة.

إنها وفق هذا التعريف أكثر من مجرد وسيلة لتوصيل المعرفةجr' . فأساليب

التدريس تقوم على أعراض معينة، لأن ثمة الطريقة تتناسب في أحوال وظروف لَّل

معينة ولا تتناسب في ظروف أخرى، وهذا يرجع إلى اختلاف الطلبة وقدراتهم

ومجتمعهم وأغراضهم • فمن ثم يسند إلى طريقة واحدة دون الآخر يحمل إلى

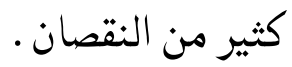

قال رشدي أحمد طعيمة بأن الطريقة الحالية في تدريس علوم البلاغة

تؤدي إلى الإخفاق في الوصول بالطلبة إلى الغاية المرجوة منها ـ فالطريقة الحالية

تفصل علوم البلاغة عن دروس الأدب، وتعالجها في حصص مستقلة بأسلوب

علمي نظري.وفوق ما في هذا الفصل من خطاً فني ، فإنه يشعر الطالب بأن درس البلاغة ثيء متكلف، فيقف منه موقف الحيرة والثك في قيمته الأدبيةIV' . ففي هذه الناحية كان الطالب يقف على حفظ القواعد والمسائل المنطقية ولا يتعلق بالذوق • وهذه من الظواهر العامة التي نجدها في تدريس البلاغة ولا سيما في

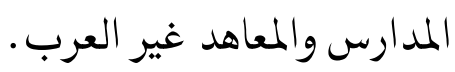

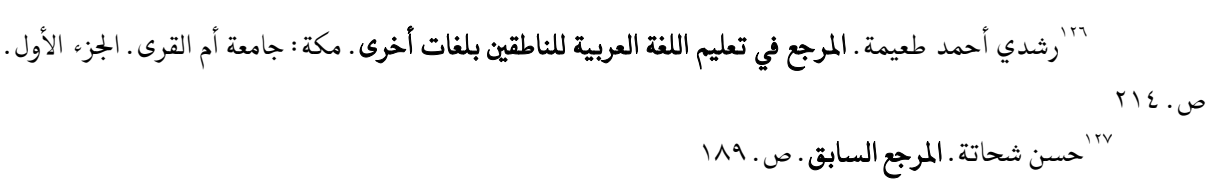


ويرى حسن شحاتة بألا يكون للبلاغة درس خاص تشرح فيه

قواعدها ، وإنما يجب أن تعلم في حصص الأدب، وفي خلال نصوصه ليتبين الطلبة منزلتها الرفيعة من الدراسات الأدبية وليسهل علينا أن نتجه بها دائما اتجاها ذوقيا خالصا لا تصوبه شائبة من علم أم فلسفة . وهو يرى بأن تدريس البلاغة بطريقة دراسة النحو من الطريقة المخطئة. فلا ينبني لمعلمي البلاغة أن يبداً الدراسة من التعريف والتحديد وضرب الأمثلة واستخراج القواعد منها . والطريقة الملائمة لتدريس البلاغة أن نبدأ بالتدريب الفني مباشرة بأن نوجه نظر الطلبة إلى نواحي القوة والجمال في النص الأدبي الذي ندرسه في حصة

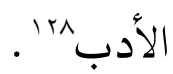

وقال طه علي حسين الدليمي وسعاد عبد الكريم الواتيلي أنّ تقسيم اللغة العربية إلى فروع هو في الواقع تقسيم مصطنع ، هدفه تيسير تدريس هذه المواد ليس إلا • ولكن تكريس هذا التقسيم وجعله أمرا واقعا أدى بالمهتمين باللغة العربية وبطرائق تدريسها إلى أن يقفوا بقوة ضد هذا التقسيم • ويرى يونس أن أساس هذا التقسيم غير سليم، لأنه أساس غير ثابت، ومن شروط التقسيم 
علم المعاني وتعليمه لغير الناطقين باللغة العربية : Ahmad Taufiq, Muhammad Ulil Fahmi

العلمي السليم ثبوت أساسه، ووجه الخطاً في تقسيم اللغة إلى هذه الفروع أن

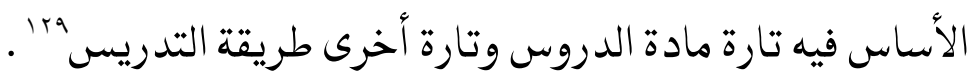

كثير من العلماء يحسّون بـأن الدراسة البلاغية الموجودة الآن لا يفيدهم

فكريا ولا وجدانيا ولا تنمي ثقافتهم آو شعورهم، وأن الموضوع كله صناعة ذهنية تدور في إطار بحريدي بعيد تماما عن متطلبات العصر وروج الأدب. ‘r'. من الآراء السابقة نعرف بأن العلماء يسعون للرجوع إلى البلاغة العربية في عصر الازدهار ، حينما كانت البلاغة تدرس بطريقة تكاملية وتستند على الفن والذوق ـ فهذه الواقعة تقع في علوم البلاغة الثلاثة، المعاني والبيان والبديع. إن طريقة التدريس تتعلق كثيرا بغرض المتعلمين وأحوالهم وقدراتهم. لذلك لا بد للمدرس أن يكون مرنا في توجيه الطريقة المتعددة . فنجاح طريقة ما في مكان معين لا يجعله ناجحا في مكان آخر بالضبط .فالطريقة تتعلق كثيرا بأهداف الدراسة.

"ra

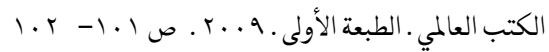

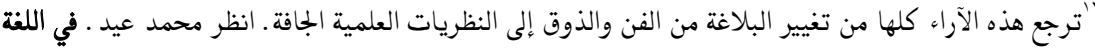

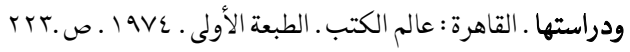


قال بعض العلماء بأن الطريقة هي أهم شيء للحصول إلى نجاح الدارسين.

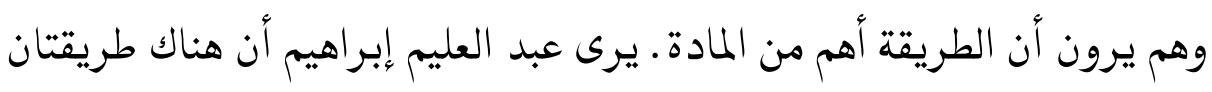

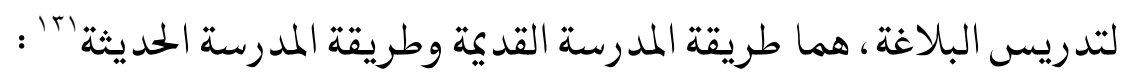

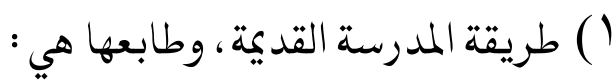
تزيق وحدة البلاغة وجعلها علوما ثلاثا

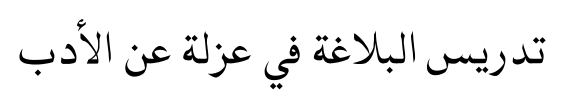

زيادة الاهتمام بالبحوث النظرية والفلسفات العميقة من التعاريف

$$
\text { والتقاسيم والضوابط }
$$

لقد أدت هذه الدراسة إلى إخفاق البلاغة وقصورها عن تحقيق غايتها من تكوين الذوق الأدبي في الطلاب وإغرائهم بتتبع الآثار الأدبية وتبين جمالها

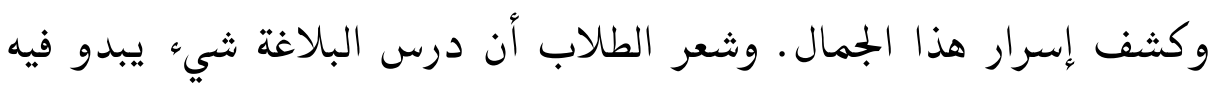
التكلف فوقفوا عليه من موقف الحيرة والشك في قيمته الأدبية. (r ) طريقة المدرسة الحديثة، وطابعها هي: أن البلاغة وحدة متكاملة ، ليس بينها فواصل

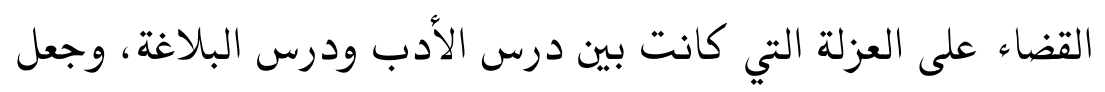

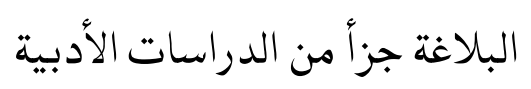

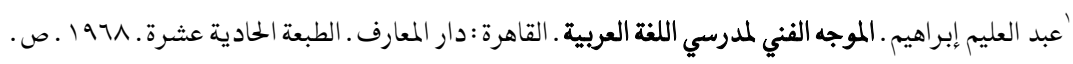
$r \cdot T-r \cdot 0$ 
علم المعاني وتعليمه لغير الناطقين باللغة العربية : Ahmad Taufiq, Muhammad Ulil Fahmi

تخففت الدراسة والمناهج الحديثة من المصطلحات البلاغية وقل الاحتفال بالتقاسيم والتعاريف والصيغ المألوفة في إجراء الاستعارات الاهتمام في درس البلاغة بتكوين الذوق الأدبي وإنضاج الحاسة الفنية معالجة الموضوعات البلاغية من الناحية النفسية الوجدانية من مبحث تاريخ البلاغة-ــمن المعرفة إلى الصناعة- ـوتقسيم عبد العليم السابق، يستخلص الباحث بأن هناك ثلاث طرق لتدريس المعاني ،وهي:

\section{ا ـ الطريقة الاستقرائية (من الأمثلة إلى القواعد)}

هذه الطريقة تعتبر طريقة قديمة وتستعمل كثيرا في تدريس القواعد r' . رأى الباحث أن هذه الطريقة طريقة حسنة في تدريس المعاني في المرحلة الابتدائية (من ناحية المعرفة اللغوية لا المرحلة المدرسية). فهذه الطريقة تناسب لمن أراد أن يعرف المعاني بطريقة أسهل وأسرع • وخطوات الدراسة بهذه الطريقة هي أن يعطي المدرس كثيرا من الأمثلة، ويقوم بالبحث لكل مثال وينتقل من مثال واحد إلى الآخر ثم يحمل المدرس فكرة الطلبة إلى المناقشة المرجوة بالطريقة الاستقرائية التي ستنتهي في استنباط القاعدة العامة والتطبيقات. وهذه ما يستعمله كثير من المعاهد الحديثة في

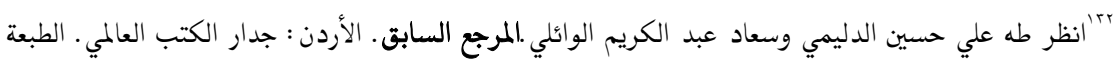

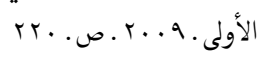

\section{IHTIMAM}


إندونيسيا مثل دار السلام غونتور فونوروغو وغيره ـ فهذه الدراسة تقصد

إلى تعريف البلاغة بوجه عام بدون التخصص فيها .

ץ. الطريقة القياسية (من القواعد إلى الأمثلة)

فهذه الطريقة تعد أقدم الطرائق المتبعة في تدريس القواعد .

وتقوم فلسفتها على انتقال الفكر من الحكم على كلي إلى الحكم على

جزئي rri . . وخطوات التدريس لهذه الطريقة هي أن يبداً المدرس بإعطاء

القواعد إلى الطلبة ويبحثونها بالتفصيل على طريقة فلسفية ومنطقية. وبعد

ما يفهم الطلبة بدقة القواعد يقوم المدرس بتوجيه فكرة الطلبة إلى الأمثلة

المتنوعة المتناسبة بدقة القواعد المدروسة، وتنتهي هذه الخطوات بالتطبيقات.

هذه الطريقة متناسب لطلبة اللغة العربية في المستوى المتوسط

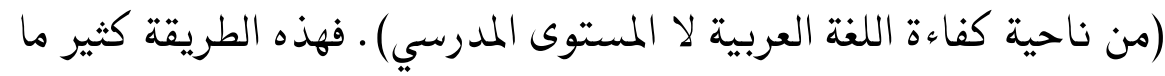

وجدناها في الكتب المدروسة المشهورة في علم البلاغة (المعاني والبيان

$$
\text { ب والبديع) مثل كتاب جواهر البلاغة وغيرة. }
$$

هذه الطريقة تعتبر طريقة قديمة وطريقة حديثة. تعتبر طريقة

قديمة من جانب البحث البلاغي في أيدي البلاغيين من الجاحظ إلى عبد

القاهر الجرجاني. وتعتبر طريقة حديثة من جانب العلماء الحديثة بعد

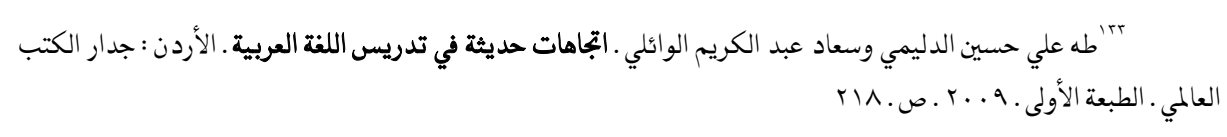


علم المعاني وتعليمه لغير الناطقين باللغة العربية : Ahmad Taufiq, Muhammad Ulil Fahmi

السكاكي الذين لا يتفقون معه .فإن الأسلوب التكاملي في بناء المنهج يهدف إلى تكين التلميذ من المحافظة على تكامل شخصية ، من خلال ما يقدم له هذا الأسلوب من معارف متكاملة، وما يكسبه من مهارات متنوعة، تنمي جوانبه العقلية والجسمية والانفعالية والاجتماعية ، حتى يسهل عليه التكيف

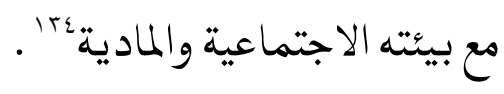

وخطوات الطريقة التكاملية في التدريس أولا بالتخطيط باختيار النصوص الأصيلة الراقية من القرآن الكريم والسنة النبوية الثريفة والأدب والنصوص، وثانيا : التنفيذ بالاستماع والقراءة جهرية كانت أم صامتة والوقوف على القضايا والمعايير والقيم، وحفظ النص والتعبير الكتابي • وثالثا : التقويم والمتابعة بتمثل تعبير الطلاب على وفق المعايير المعينة ومعالجة الأخطاء اللغوية الثائعة في تعبير الطلاب. وهذه الطريقة يناسب لمتعلمي اللغة والأدب في المرحلة المتقدمة من المتخصصين في البلاغة ولمتعلمي اللغة العربية للناطق

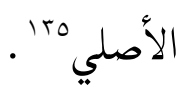
ج • الملخص

علم المعاني هو العلم الباحث في مسائل مطابقة الكلام بالسياق، والغرض منه لأن يكون الكام الذي يقصده المتكلم لإيصاله إلى ذهن السامع

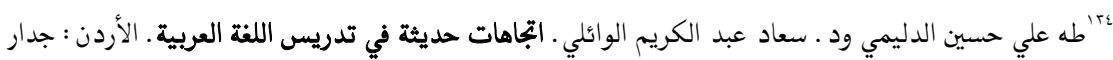

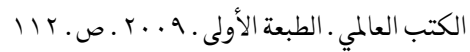

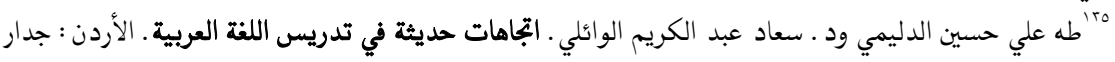

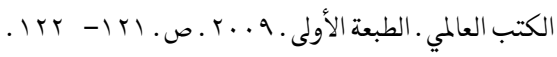

\section{IHTIMAM}


بليغا ـ علم المعاني هو العلم الأول لا بد منه قبل العلمين اللذين يأتيين بعده، فعلم

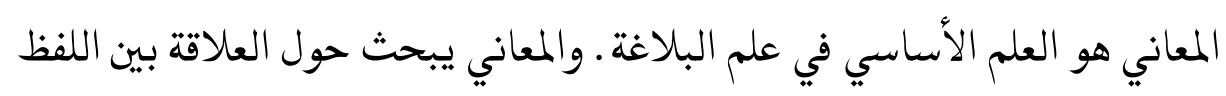

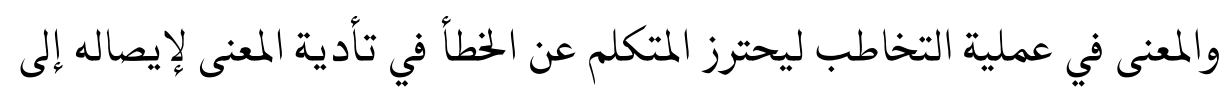
المخاطب.

فإن طريقة التدريس تتعلق كثيرا بغرض المتعلمين وأحوالهم

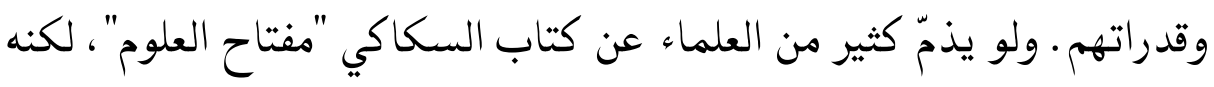

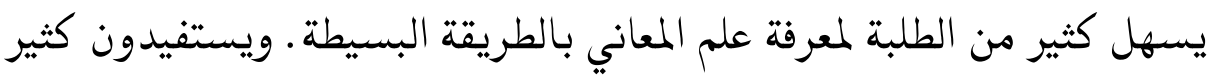

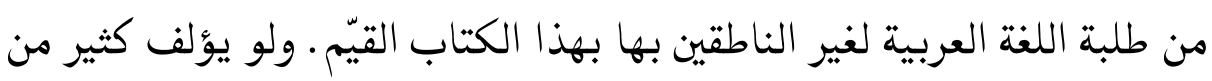
مؤلفي كتب البلاغة في طريقة واحدة لتعطلت بقية احتياج القراء ومتعلمي اللغة العربية.

الطريقة التي نستطيع أن نستعملها في عملية الدراسة يرجع إلى

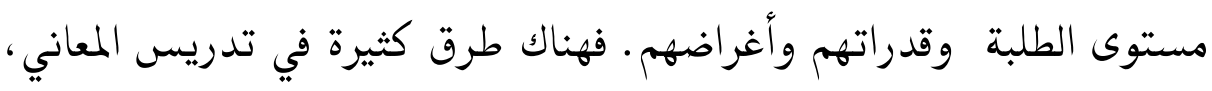

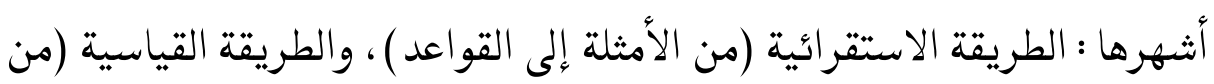
القواعد إلى الأمثلة)، والطريقة التكاملية (بين البلاغة والأدب والنقد ). 
علم المعاني وتعليمه لغير الناطقين باللغة العربية : Ahmad Taufiq, Muhammad Ulil Fahmi

\section{المراجع}

إبراهيم، عبد العليم الموجه الفني لمدرسي اللغة العربية. القاهرة : دار المعارف.

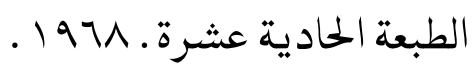

الاسكندري، أحمد، و مصطفي عناني. 1917 ـ الوسيط في الأدب العربي

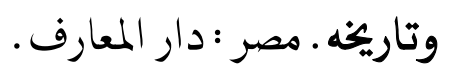

الجابري، عبيد · بنية العقل العربي. بيروت: دار البيداء. .... . الطبعة

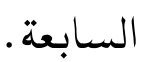

حسان، تمام. الأصول : دراسة إبستيمولوجية للفكر اللغوي عند العرب.

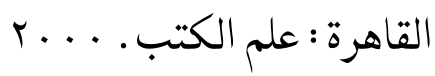

الدليمي، طه علي حسين ود . سعاد عبد الكريم الوائلي. التجاهات حديثة في

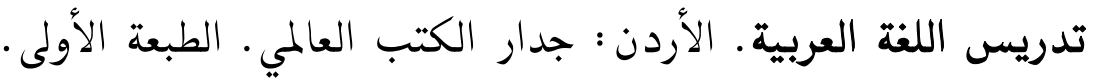
. r.. 9

زايد، عبد الرزاق أبو زيد. تطور مفهوم البلاغة في صناعة الكتاب الفنية.

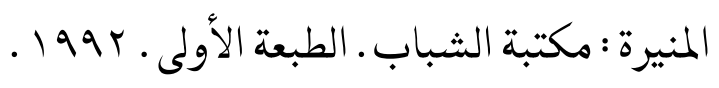

السكاكي، يوسف بن أبي بكر يعقوب بن علي مفتاح العلوم· بيروت : دار الكتب العلمية ـ الطبعة الثانية. IAAV

شايب، أحمد ـ أصول النقد الأدبي. مصر : مكتبة النهضة. الطبعة السابعة. $.197 \varepsilon$

\section{2}


شحاتة، حسن • تعليم اللغو العربية بين النظرية والتطبيق . القاهرة : الدار المصرية

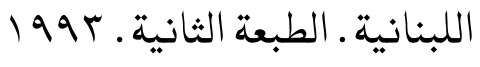

ضيف، شوقي · البلاغة : تطور وتاريخ . القاهرة : دار المعارف. الطبعة الرابعة. .1970

طعيمة، رشدي أحمد طعيمة. المرجع في تعليم اللغة العربية للناطقين بلغات أخرى . مكة : جامعة أم القرى. الجزء الأول.

عباس، فضل حسن ـ البلاغة العربية فنونها وأفنانها ـ عمان : دار الفرقان ـ الطبعة

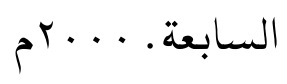

عيد ، محمد ـ في اللغة ودراستها ـ القاهرة : عالم الكتب ـ الطبعة الأولى . $19 V$ ـ . الميداني، عبد الرحمن · البلاغة العربية أساسها وعلومها وفنونها . المكتبة

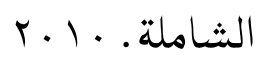

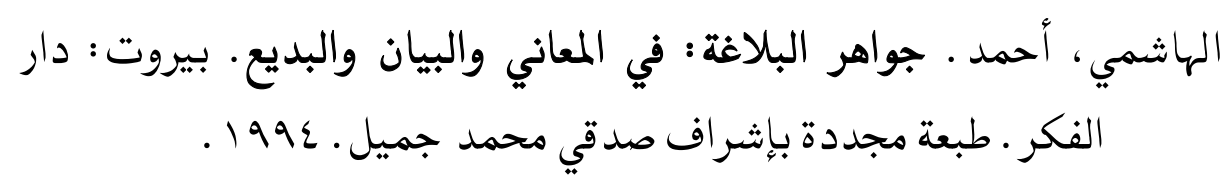

Asrori, Imam. Ekuivalensi antara Pragmatik dan Ilmu Ma'ani. Jurnal alHadharah. Tahun I, NO. I. Januari 2001

Sudjiman, Panuti dan Aart Van Zoest, edd. all. Serba-Serbi Semiotika, Jakarta: Gramedia Pustaka. 1992. 